\title{
PREVALENCE OF CONGENITAL HEART DISEASE IN UMERKOT
}

\author{
Mohsin Saif, Abdul Fatah*, Waqas Akhtar*, Farah Javed*, Ali Mujtaba Tahir*, Muhammad Hussain* \\ Armed Forces Institute of Cardiology/National Institute of Heart Disease (AFIC/NIHD)/National University of Medical Sciences (NUMS) \\ Rawalpindi Pakistan, *Combined Military Hospital Chhor/ National University of Medical Sciences (NUMS) Rawalpindi Pakistan
}

\section{ABSTRACT}

Objective: To study the prevalence and the pattern of distribution of congenital heart disease.

Study Design: Descriptive cross-sectional study.

Place and Duration of Study: The study was conducted at outpatient department (OPD) of CMH Chhor and DHQ Umerkot, Sindh (Pakistan), from Dec 2019 to Mar 2020.

Methodology: All the children ( $<12$ years age) presenting to Paediatric OPD of the two hospitals were enrolled into study. Any patient with either a history or clinical examination pointing towards a suspected congenital heart disease was referred to Paediatric Cardiologist for 2-D echocardiogram. Details of the patient were recorded on designated proforma.

Results: A total of 273 patients were diagnosed with congenital heart disease. Out of these, $114(41.7 \%)$ were female and 159 (58.2\%) were male (male: female of 1.4:1). The age of the children was ranging from 2 months to 12 years, $153(56.04 \%)$ had simple heart defects, while 120 (43.9\%) had complex or multiple congenital heart anomalies. Amongst the 273 patients, $25.3 \%$ were cyanotic and $74.7 \%$ had acyanotic heart disease. Most common lesion identified was ventricular septal defect (29.6\%), followed by Tetralogy of Fallot in $20.8 \%$.

Conclusion: Acyanotic heart defects confirms to the major bulk of congenital heart defects with male preponderance.

Keywords: Acyanotic, Congenital heart disease, Cyanotic.

This is an Open Access article distributed under the terms of the Creative Commons Attribution License (http://creativecommons.org/licenses/by/4.0), which permits unrestricted use, distribution, and reproduction in any medium, provided the original work is properly cited.

\section{INTRODUCTION}

Cardiac diseases of congenital origin still remain the most widespread diseases of heart affecting children especially in first year of life ${ }^{1}$. There are different types of congenital heart defects which can be broadly classified as simple defects and complex defects. It is the most common single group of congenital abnormalities accounting for about 30 percent of the total and has high mortality rate during infancy, depending on the type and severity of lesion². It is necessary to mention that the heart ailment is a defect or abnormality, not a disease ${ }^{3}$. Congenital heart defects are seen in isolation or in association with syndromes. The defects can be broadly classified into cyanotic and acyanotic heart defects depending upon their physiology $y^{4}$

In Pakistan about 40,000 children are born with a congenital heart defect annually. Incidence

Correspondence: Dr Mohsin Saif, Consultant Cardiologist, AFIC/NIHD, Rawalpindi Pakistan was found to be 8.2/1000 live births in a study in China, 25/1000 live births in Bangladesh, and $8.1 / 1000$ live births in a study in Atlanta 5 .

Pediatric cardiology is a relatively newer field in a developing country like Pakistan. Many cases of congenital heart disease are diagnosed only incidentally as they comes across medical facility for some other issue. There is no national data registry in Pakistan so exact incidence is yet to be known' ${ }^{6}$. Home deliveries or deliveries through untrained birth attendants are a major obstacle in screening children with CHD. High percentage of deliveries carried outside the hospital setting are either because of financial constraints, unavailability of adequate health facility nearby or social taboos. Home deliveries by untrained birth attendants accounted for $77.1 \%$ of all deliveries and amounted to $88.6 \%$ of all children with delayed diagnosis. Almost all patients delivered at home (97\%) had a delayed diagnosis. With limited resources, providing additional hospital services may not be an option in short 
term but training birth attendants to identify and refer such patients for consultation can be very helpful in avoiding delays in diagnosis7. Since data regarding the prevalence and type of congenital heart diseases occurring in rural health population is scanty, the purpose of our study is to identify patients of congenital heart disease based upon their respiratory symptoms, clinical examination and echo-cardiography; the variety of heart diseases in relation to age; burden of the disease on rural population in interior Sindh.

\section{METHODOLOGY}

The study was descriptive cross sectional conducted at Paeds OPD of CMH Chhor and Cardiac Centre Umerkot, Sindh, from December 2019 to March 2020. Sample size collected was 273 in total after applying inclusion and exclusion criteria.

All patients presenting to OPD with recurrent respiratory symptoms and a cardiac murmur, or asymptomatic with cardiac murmur on examination were included, who were of 2 months to 12 years of age regardless of ethnicity, religion and social status. Patients having respiratory diseases like Asthma, bronchitis, pneumonia; respiratory symptoms of non cardiac origin like anemia, volume overload; and acquired heart diseases were excluded. Data including name, age, sex, hospital registration number to avoid duplication, and presenting complaints were recorded after taking informed consent from the patient's parents or attendants. All patients underwent 2D transthoracic Echocardiogram by a Paediatric cardiologist to confirm the diagnosis and record the type of cardiac anomaly. Chest $X$ ray and biochemical profile were done to exclude non cardiac causes.

Computer based software SPSS version 20.0 was applied for analysis of collected data. Descriptive statistics presented for qualitative and quantitative variables. Frequencies and percentages calculated for gender, simple and complex heart diseases. Mean \pm SD for age, weight were calculated. Effect modifiers as age, gender was managed by stratification, post stratification and chi-square test were used keeping $p \leq 0.05$ as significant.

\section{RESULTS}

Out of a total of 273 patients, most were males and a little less than half were females (fig$1)$. This was in correspondence with the studies held in different areas of Pakistan 1,2,5,6,8.

Regarding the type of lesion, acyanotic heart defects account frequently of the total cases amongst which ventricular septal defect (VSD)

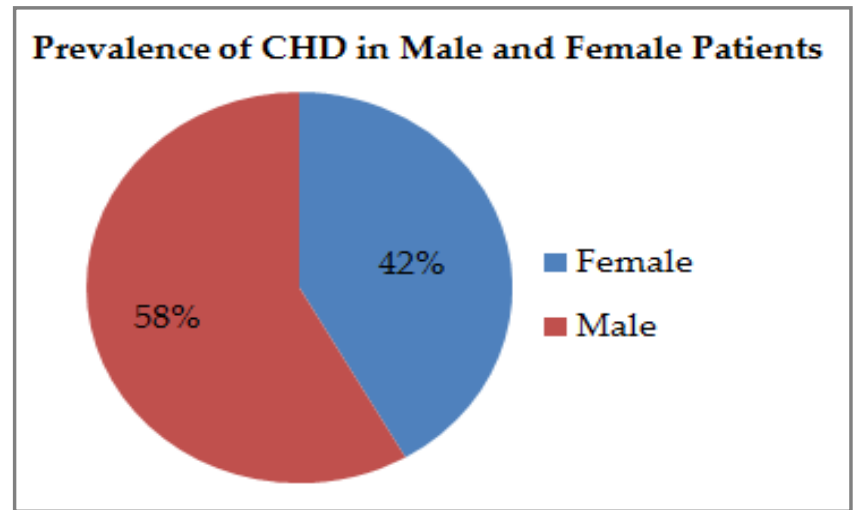

Figure-1: Gender distribution amongst congenital heart disease patients.

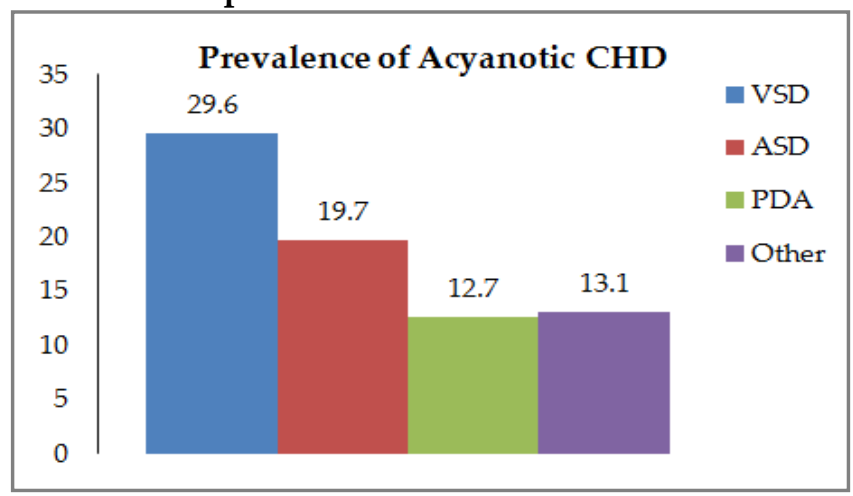

Figure-2: Percentage prevalence of types of acyanotic chronic kidney diseases.

was the commonest, followed by atrial septal defect (ASD) and less commonly Patent ductus arteriosus (PDA). Other valvular defects and outlet obstructive lesions which include double outflow right ventricle, mitral valve lesions and aortic valve lesions account for the least likely occurrence in both genders. The preponderance of acyanotic heart diseases is seen in other national studies as well, amongst which the com- 
monest lesion seen is Ventricular septal defect (fig-2) $1,2,5,6,8$.

In this study, cyanotic heart diseases make up for $25.3 \%$ of the cases, out of which Tetralogy of Fallot was the most commonly found the presentation was with failure to thrive, recurrent infections and feeding difficulties. It is found mostly in younger individuals. Transposition of Great Arteries (TGA) and Pulmonary stenosis were the next to follow in occurrence but were very less in number. Only one case of Eisenmenger syndrome in a young female was detected in the population studied (fig-3).

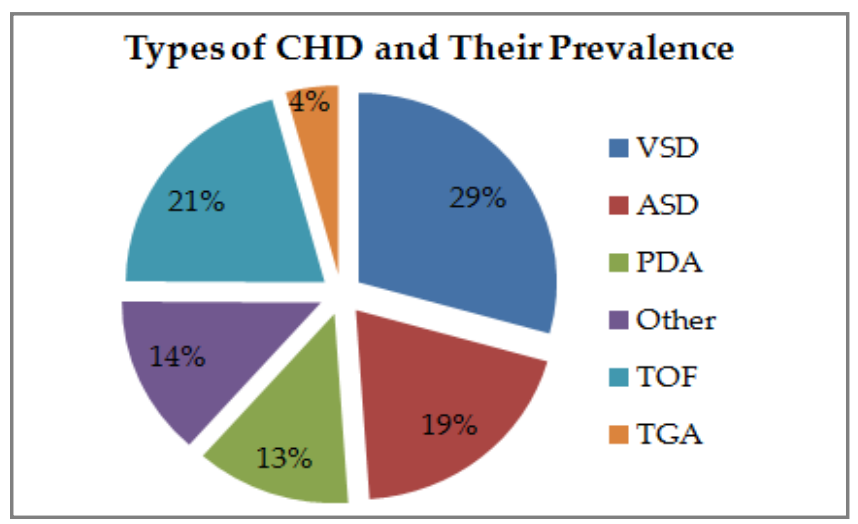

Figure-3: Percentage of all types of chd in the total sample population.

Further distribution of CHD into simple and complex or multiple heart defects reveals that simple heart defects make up for a little more than half of the total cases whereas complex or multiple lesions comprise the other lesser half.

Distribution of the heart defects on the basis of age reveals that acyanotic heart diseases are frequent in later ages as the lesions become symptomatic in later age and remain dormant in the early age when body requirements for nourishment are less and body is able to compensate for minor changes in oxygenation of blood. Mean age of prevalence or detection of acyanotic and cyanotic heart defects is shown in the table below (table).

\section{DISCUSSION}

Congenital heart disease is the most common congenital defect and had higher mortality than any of other birth defects during early years of life. Word "congenital" means existing at birth. The term 'Congenital heart defect' and 'Congenital heart disease' are often used to mean same thing 9 . The incidence, prevalence and pattern of distribution of congenital heart disease types vary from region to region. The meta analysis reports that analyzed 114 studies from all over the world, showed that highest birth prevalence of CHD 9.3/1000 live births is in Asia10. In our country the only reported incidence is $4 / 1000$ live births ${ }^{11}$. However, the birth prevalence of $8 / 1000$ live births is generally accepted ${ }^{12,13}$. In general congenital heart diseases vary from simple def-

Table: Mean age at presentation of various types of chronic heart disease.

\begin{tabular}{c|l|c}
\hline $\begin{array}{c}\text { S. } \\
\text { No. }\end{array}$ & $\begin{array}{l}\text { Types of Chronic Heart } \\
\text { Disease }\end{array}$ & $\begin{array}{c}\text { Mean Age at } \\
\text { Presentation } \\
\text { (Years) }\end{array}$ \\
\hline 1 & Ventricular Septal Defect & 6.1 \\
\hline 2 & Atrial Septal Defect & 7 \\
\hline 3 & Patent Ductus Arteriosus & 4.2 \\
\hline 4 & $\begin{array}{l}\text { Obstructive or Valvular } \\
\text { Congenital Lesion }\end{array}$ & 8.1 \\
\hline 5 & Tetralogy of Fallot & 5.1
\end{tabular}

ects to severe malforma-tions, early diagnosis and prompt treatment is required to reduce mortality ${ }^{14}$. Congenital heart malformation in newborn babies with low birth weight is significantly higher than with baby born with appropriate weight for age ${ }^{15}$.

A total of 273 patients of district Umerkot and Chhor were included in this study with male accounts for $58.2 \%$ and female were $41.7 \%$. A study in Abbottabad also reported CHD to be more prevalent in male i.e. $64 \%$ as compared to female $36 \% 16$. VSD was the most common congenital cardiac lesion in our study (accounts for $29.6 \%$ ). This is comparable to other studies worldwide as they also reported VSD being the commonest defect. A study conducted in Kanpur, India also showed ventricular septal defect to be the most common ${ }^{17}$. The frequency of different acyanotic cardiac defects in our study were found to be $74.7 \%$ with Ventricular septal defect (VSD) 29.6\%, Atrial septal defect (ASD) 19.7\%, Patent 
ductus arteriosis (PDA) $12.7 \%$, Pulmonary stenosis (PS) $2.1 \%$ and valvular defects and obstructive lesion $13.6 \%$. Similar results are reported in a study from Czechoslovakia where frequency of different cardiac lesion were Ventricular septal defect (VSD) 31.4\%, Atrial septal defect (ASD) $11.37 \%$, Pulmonary stenosis (PS) 7.1\%, Patent ductus arteriosis (PDA) $4.75 \%$, and Pulnonaryartesia (PA) $2.38 \% 18$.

Tetralogy of fallot (TOF), an important cyanotic congenital heart disease, comprised of four structural defects including overriding of aorta, pulmonary stenosis, right ventricular hypertrophy and ventricular septal defect ${ }^{19}$. In our study, cyanotic diseases account for $25.3 \%$, Tetralogy of Fallot was the most common cyanotic CHD which accounts for $20.8 \%$. This is similar to a study conducted in Karachi in which tetralogy of Fallot accounts for $24.4 \%$. Our study is comparable with other studies across country conducted in Hazara, Lady Reading Hospital Peshawar and AKUH, as they exhibited Ventricular septal defect as the most common acyanotic and Tetralogy of Fallot as the most common cyanotic heart disease $20,21,11$.

\section{CONCLUSION}

Congenital heart disease is common and undiagnosed in the population of interior Sindh due to unavailability and inaccessibility of cardiac centers. Amongst these, acyanotic and simple congenital heart defects are common and mostly male population is affected. Considering the prevalence of this disease, early diagnosis requiring echo-cardiography and prompt treatment is key to survival of many children in remote areas of Sindh, Pakistan.

\section{CONFLICT OF INTEREST}

This study has no conflict of interest to be declared by any author.

\section{REFERENCES}

1. Jamali A, Kanhar I. Congenital heart diseases: frequency of different acyanotic and cyanotic lesions in children. Int Res J
Pharm Med Sci 2018; 1(3): 41-45.

2. Patel N, Jawed S, Nigar N, Junaid F, Wadood A, Abdullah F. Frquency and pattern of congenital heart defects in a tertiary care cardiac hospital of Karachi. Pak J Med Sci 2016; 32(1): 79-84.

3. Oliver JM, Gallego P, Gonzalez AE, Hamilton DG, Avila P, Yotti $\mathrm{R}$, et al. Risk factors for excess mortality in adults with congenital heart diseases. Eur Heart J 2017; 38: 1233-41.

4. Linde D, Konings EE, Slager MA, Witsenburg M, Helbing WA, Takkenberg JJ, et al. Birth prevalence of congenital heart diseases worldwide: asystematic review and metaanalysis. J Am Coll Cardiol 2011; 58(21): 2241-47.

5. Hussain S, Sabir M, Afzal M, Asghar M. Incidence of congenital heart disease among neonates in a neonatal unit of a tertiary care hospital. J Pak Med Assoc 2014; 64(2): 175-78.

6. Sehar T, Sheikh AM, Kanwal A. To identify pattern of congenital heart diseases in a newly developed tertiary care unit. Pak Armed Forces Med J 2019; 69(4): 831-36.

7. Rashid U, Qureshi A. Pattern of congenital heart disease in a developing country tertiary care center: factors associated with delayed diagnosis. Ann Pediatr Card 2016; 9(3): 210-15.

8. Mohammad N, Shaikh S, Memon S. Spectrum of heart disease in children under 5 years of age at Liaquat University Hospital, Hyderabad, Pakistan. Indian Heart J 2014; 66(1): 145-49.

9. Videbæk J, Laursen HB, Olsen M, Høfsten DE, Johnsen SP. Long-term nationwide followup study of simple congenital heart disease diagnosed in otherwise healthy children. Circulation 2016; 133: 474-83.

10. Van der Linde D, Konings EE, Slager MA, Witsenburg M, Helbing WA, Takkenberg JJ, et al. Birth prevalence of congenital heart disease worldwide: a systematic review and metaanalysis. J Am Coll Cardiol 2011; 58(21): 2241-47.

11. Hassan I, Haleem AA, Bhutta ZA. Profile and risk factors of congenital heart disease. J Pak Med Assoc 1997; 47(3): 78-81.

12. Wang T, Chen L, Yang T, Huang P, Wang L, et al. Congenital Heart Disease and Risk of Cardiovascular Disease: A MetaAnalysis of Cohort Studies. J Am Heart Assoc 2019; 8(10): 1-11.

13. Abqari S, Gupta A, Shahab T, Rabbani MU, Ali SM, Firdaus U. Profile and risk factors for congenital heart defects: A study in a tertiary care hospital. Ann Pediatr Cardiol 2016; 9(3): 216-21.

14. Celik M, Aldudak B. Problems of the neonates with congenital heart disease requiring early interventions: a regional report. Turk Pediatri Ars 2015; 50(3): 158-62.

15. Luca AC, Holoc AS, Iordache C. Congenital Heart Malformations In Newborn Babies With Low Birth Weight. Rev Med Chir Soc Med Nat Iasi 2015; 119(2): 353-60.

16. Bibi S, Gilani S. Spectrum of congenital heart disease in full term neonates. J Ayub Med Coll Abbottabad 2018; 30(1): 67-70.

17. Kapoor R, Gupta S. Prevalence of congenital heart disease, Kanpur, India. Indian J Pediatr 2008; 45: 309-11.

18. Samánek $M$, Slavík Z, Zborilová $B$, Hrobonová V, Vorísková $M$, Skovránek J. Prevalence, treatment, and outcome of heart disease in live-born children: a prospective analysis of 91,823 live-born children. Pediatr Cardiol 1989; 10(4): 205-11.

19. Page GG. Tetralogy of Fallot. Heart Lung 1986; 15(4): 390-401.

20. Burki MK, Babar GS. Prevalence and pattern of congenital heart disease in Hazara. J Ayub Med Coll Abbottabad 2001; 13(4): 16-18.

21. Aman W, Sherin A, Hafizullah M. Frequency of congenital heart disease in patients under the age of twelve in Peshawar. J Postgrad Med 2006; 9(1): 64-69. 